\title{
University museums and the Third Mission: the project "Young people for culture" in the Museum Laboratory of Education of Bologna University
}

\author{
Chiara Panciroli ${ }^{\mathrm{a}}$, Anita Macauda ${ }^{\mathrm{b}}$ \\ ${ }^{a}$ University of Bologna, Italy, chiara.panciroli@unibo.it \\ ${ }^{b}$ University of Bologna, Italy, anita.macauda@unibo.it
}

\begin{abstract}
The university has been called to run a Third mission of a socio-entrepreneurial nature that deals with the interaction in communities favouring the use of knowledge to contribute to social, cultural and economic development in society. This study case can fit in the main objectives of the mission in which public and local assets, such as museums, become accessible to everyone. The ModE project - the Musueum Laboratory of Education of Bologna University - has been included in this context with reference to the widespread diffusion of the teaching of cultural heritage.

Summing up, the aim of the project "I giovani per la cultura" is to prepare and strengthen the professional profiles of cultural heritage, in particular by museum educators, cultural mediators and teachers, who, according to a training plan "domino effect", become educators themselves and, along with young people, achieve high-quality experiences with our wealth of museums.
\end{abstract}

Keywords: training; cultural heritage; education; e-learning content; youth

\section{Introduction}

The scientific community recognises the University as a priority organisation that deals with constant research efforts with regard to innovation in teaching, promotion of technology transfer projects and development of spaces with the aim of implementing professional training as the result of organisation of a constantly updated programme.

Along with these two fundamental objectives in teaching (the first mission is based on interaction with students) and research (the second mission is based mainly on interaction with the scientific community or similar entities), the University has been called on to run a third mission of a socio-entrepreneurial nature, which deals with the interaction between communities. Specifically, the University should support/facilitate the use of knowledge for social, cultural and economic development in society ${ }^{1}$. In this context, every structure within the university should communicate and spread knowledge through a close relationship with local institutions and people.

Knowledge is certainly more accessible, but at the same time, superficial and redundant. There is a shared view that a society without knowledge cannot have a future; on the other hand, in the age of globalisation, characterised by the coexistence of different cultures and visual codes that integrate quickly into physical and virtual realities, contemporary societies witness radical changes to knowledge itself, that, although more accessible and explorable on the one hand, is presented as highly varied and sometimes superficial and redundant on the other.

\footnotetext{
${ }^{1}$ This topic was discussed in Rome at the convention "Third Mission and Technological Transfer: the role of Cnr of the University" (15th June 2016), organized by the National Research Council and the Università degli Studi di Roma "Tor Vergata".[AU: Please provide full form for "Cnr" in footnote 1 if applicable.]
} 


\section{University museums and the Third Mission: the project "Young people for culture" in the Museum Laboratory of Education of Bologna University \\ Panciroli, Macauda}

Determining this transformation is the growing use of electronic networks by every individual as well as every corporate and social environment. These structures act as a support, especially communicatively, radically changing contexts and daily practices. In this way, the training world has also been seen to greatly expand the spaces and range of problems in which both the world of formal education, specifically schools and universities, and the informal sphere, with particular reference to museums, are transformed from spaces of codified knowledge to laboratories for the acquisition of knowledge in the making, in view of and with the total involvement of the person.

These changes are also based on the assumption that knowledge is not only passed on by means of predefined, rigid methods but must also activate cognitive and emotional reconstruction processes in individuals, aimed at achieving the sharing and construction of original, cultural projects (Panciroli, 2007). The subject is therefore no longer understood to be an uncritical consumer of knowledge but a constructor and interpreter of information. This knowledge, restated for comparison within different contexts, should be concretely used in interactive communication processes in order to achieve the evolution of the collective social intelligence (encultured knowledge) necessary to participate conscientiously in life's situations.

Therefore, the case study proposes ranks among the principal dimensions of the third mission, in which public assets and/or collective local assets, among which are cultural goods and museums, are understood to be goods of a sociocultural nature accessible to the public. In this way, the museum becomes an "incubator" of the university's third mission, an innovative hub capable of uniting and encouraging the mutual legitimisation of the three functions recognised by the university, namely, scientific research, education training and social responsibility.

This article tries to highlight how contexts such as cultural heritage, among which are the museums, can compete with this change, in line with what was indicated in the research called "L'Università italiana come un museo: viaggio nelle collezioni universitarie", that is, "Italian Universities like Museums: journey through university collections", which gives a complicated and quite unknown map of Italy's cultural heritage. Specifically, the research highlights Italian universities' efforts in reorganising their assets and the attempt to make their accessibility effective and efficient, convinced that cultural, humanistic and scientific assets are an opportunity for essential training to impart interest and passion in the young, starting from their own roots (Decreto della "Buona Scuola", Legge 107/2015).

The first part deals with the so called "Third Mission" that should be carried out by universities.

The second part defines the close relation between universities and museums; the conclusion describes the technological experiments carried out by an innovative museum.

\section{Museums and universities: a relationship under construction}

The "balance sheet" of Italian universities is not usually accompanied by an effectively accessible system, nor is it accompanied by a common strategy that responds to the shared mission. To understand in what direction the universities' cultural heritage is heading, we could start from the mission that should direct the management of such heritage. The evolution of this mission, in fact, has taken shape due to the national and international debate and also due to the specific actions that followed, which highlight the strategic role of the assets and the university museums. In this sense, the first reference at a national level is the Museums' Commission of the Conference of Italian University Rectors (CRUI), which in 1999 was given the responsibility of promoting the development initiatives of the assets that the rectors preserve. At an international level, an important step was taken towards the idea of university museums as a window for a vast public, when, in 2000, the Declaration of Halle was signed by twelve European universities. Its subtitle was as follows: "Academic Heritage and Universities: Responsibility and Public Access", and it was the founding document of the Universeum network. In the declaration, the collections and the university

${ }^{2}$ Presented in Parma on December $16^{\text {th }} 2015$, the result of the research was reported by Marilena Pirrelli in Art Economy 24 in Il Sole 24 ORE. 


\section{University museums and the Third Mission: the project "Young people for culture" in the Museum Laboratory of Education of Bologna University \\ Panciroli, Macauda}

museums are considered a great opportunity to live and participate in university life. The materials contained have since been used as instruments for training, research and the diffusion of culture.

The following year, the International Council of Museums (ICOM), when founding the Committee for University Museums and Collections (UMAC), recognised the need to express the work taking into account the university heritage. In fact, UMAC considers the collections and university museums a point of contact between the university and the surrounding community and also as a useful instrument in the promotion of the university itself. In the display of their intentions, in this regard, it reads, "university collection and their curators are important interdisciplinary links for the community. Collections enhance teaching and research. They promote a positive image of the institution and provide welcoming access points to the campus (...). In general these will reflect the goals of the university as well as the aim of research, teaching and community service" (UMAC, 2004).

In 2005, the Committee of Ministers of the European Council drew up the "Recommendation on the Governance and Management of University Heritage" (REC/2005/13), containing some important indications on different topics (protection, management, research, professional training, development and use) linked to the cultural, tangible and intangible heritage of universities, with an explicit reference to museums, libraries and archives. In 2009, a project financed by the European Commission led to the drafting of the Green Paper of the Third Mission of Universities in 2012 (E3M Project, 2012). In about ten years, opinion has changed from the consideration of the university assets as an active resource for teaching and research to the idea to activate a new role of universities that, apart from research and teaching, encourages social inclusion, also by means of involvement of the public in their museums (Sobrero, Spigarelli, 2015).

In 2013, the National Agency for the Evaluation of the University System and Research (ANVUR) placed the museums among the activities of the Third Mission, capable of producing positive impacts even outside of the university communities and also beyond the economic value of knowledge. In fact, the Third Mission has been distinguished in cultural and social terms as a mission that produces public assets that increase the welfare of the society. It reads, "such assets can have cultural content (events and cultural assets, management of museum centres, archaeological excavations, scientific disclosure), social (public health, activities that benefit the community, technical/professional advice given in teams), educational (adult education, lifelong learning, continuous training) or civil awareness" (ANVUR 2013).

In conclusion, there was an important request made by ANVUR in 2015 to Italian universities with regards the measurement (by means of an auto-evaluation form entitled SUA-RD Third mission) of the presence of museum centres, of the management process of cultural assets and historical property, and of activities, as defined by public engagement, which are of non-profit nature and with educational and cultural value, as well as aid in the development of society, from which emerges the importance of the communities' need to take advantage of university museums (ANVUR, 2015).

An important project called "The Network of Italian University Museums" has been inserted into this debate. It was coordinated by the University of Modena and Reggio Emilia (2012-2015), with the aim of "promoting openness to lifelong learning activities for different audiences", passing from "inventory and cataloguing of museum artefacts and objects" (2012) to the strengthening of community identity, the promotion of environmental education and the welfare of citizens, by means of designing new sections or welcoming strategies for the museums, which in turn contribute to the openness to different audiences.

This brief overview highlights how, at the beginning of the debate, the theme was prevalently centred on how to make the display system of the assets effective, particularly relevant for study and research. Today, it is necessary, although it is still more in theory than practice, that the European and Italian universities take on the responsibility of a role that goes beyond the boundaries of the Universities' institutional missions (i.e. research and teaching) towards an "agency with a cognitive function to extend educational resources to nonuniversity audiences and communities" (Mannino, 2016).

In this regard, a theme has been opened of cultural heritage and museum education, attested to by extensive literature (Hein, 1998; Hooper Greenhill, 1999; Bollo 2008; Brunelli 2011; De Biase 2014; 


\section{University museums and the Third Mission: the project "Young people for culture" in the Museum Laboratory of Education of Bologna University \\ Panciroli, Macauda}

Cenedella, Mascheroni, 2014; Panciroli 2016b), which highlights the experiences of established and widespread educational services that outline a very articulated and interesting reality from a social and entrepreneurial point of view. Therefore, the development framework of mediation services and cultural heritage education in museums and other university sites is not yet well defined. In fact, although there are now many museum centres and individual university museums that guarantee training opportunities and educational excellence, it is still, in part, unknown how the universities organise these kinds of services, also in terms of ownership of major development schemes such as the design, management and delivery. This also introduces the theme of professionalism of the reference figures that are necessary to ensure the scientific quality of such structures: in this regard, we are talking about designers, managers, communicators, educators and mediators. The recent national debate highlighted how museum services, also according to Article 117 of the D.L. 42/2004 (Code of Cultural Assets and of the Landscape), are an "essential service" comparable to other public welfare services, services that could be called cognitive welfare, on a par with schools, libraries and archives. The Italian universities today have a great opportunity that consists not only of the extraordinary dimensions of their own cultural heritage but also of the possibility that these assets could become an effective instrument of external communication. This communication is essential and it would permit the decrease in the distance that often separates the cognitive, "high" institutions and daily life, making visible the fact that the universities, first of all, are public institutions that manage public assets and that can perform a significant role in social communication, active inclusion and training for new professional skills.

It is in this way that the project proposal of the Museum Laboratory of Education in the Department of Educational Sciences in the University of Bologna - MOdE - has been introduced with specific reference to the methodologies aimed at spreading the teaching of cultural heritage through the use of technology.

\section{The Museum Laboratory of Education: an integrated environment for research and training}

The Museum Laboratory of Education (MOdE) ${ }^{3}$ is the expression of a research project created in 2008 by the Department of Educational Sciences, "Giovanni Maria Bertin", in the University of Bologna. Specifically, MOdE is a virtual environment aimed at the display, valourisation and diffusion of the "objects" of Educational Sciences, and it meets some basic needs:

- It recognises that education, as well as its multiple branches (school, outside of school and family), has a tangible, historical and cultural substance with highly varied fields of study and research, so as to create a landmark of great institutional value in a specific museum.

- It supplies resources in different learning contexts to experiment innovative teaching that ensures that students, teachers and trainers have the use of technology, with particular reference to potential elearning to construct the sharing of knowledge.

- It offers a research space to get to know, experiment and share the tangible and intangible testimonials of educational culture that involves the participation of a vast community of practice composed of, in particular, experts in the field of museum education and cultural heritage.

This is how MOdE proposes a divided structure, open to various learning contexts - both formal and informal - on the territory.

\subsection{The Technological Architecture of MOdE}

MOdE is an integrated system composed of three basic areas: an exhibition area, a documentation area and an e-learning area, all of which are supported by a specific technological platform.

\footnotetext{
${ }^{3}$ MOdE's website: http://www.mode.unibo.it
} 


\section{University museums and the Third Mission: the project "Young people for culture" in the Museum Laboratory of Education of Bologna University \\ Panciroli, Macauda}

The exhibition area $^{4}$ represents a place for the conservation and display of the "objects" of expression of the Educational Sciences. It is divided into two specific virtual settings: the rooms of an interdisciplinary nature (Special Education room, the Ernesta Galletti Stoppa room, the children's room) and the studios, open places with a strong laboratorial nature used for research and experimentation (Panciroli, 2016a). For every "object" catalogued using the Dublin Core system, a number of descriptions are supplied along with comments, explanations, details, enlarged photos and audio-visual material.

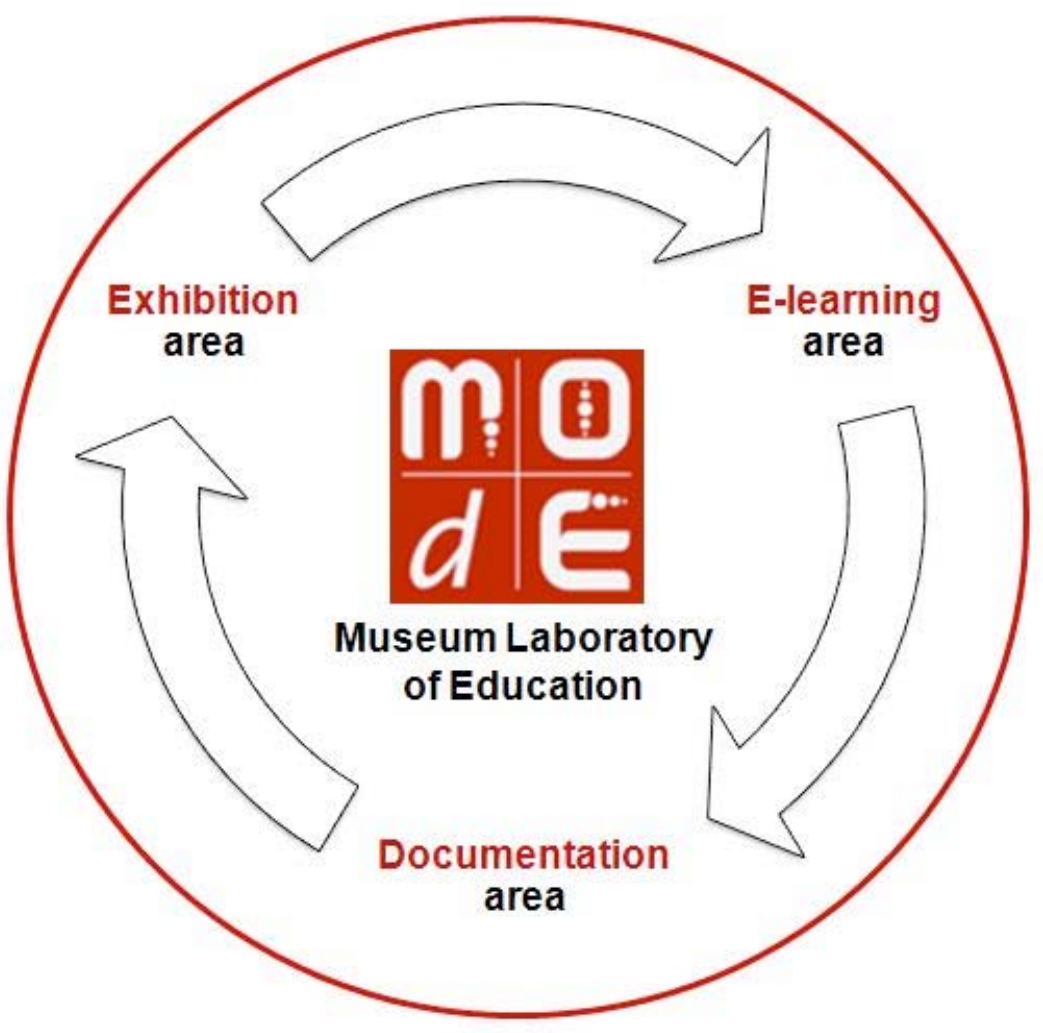

Fig. 1. The areas of MOdE

The e-learning area $^{5}$ delivers educational content (Learning Object) with a modular unit system, aimed at helping the acquisition and development of basic skills in the theme of cultural heritage, as well as the educational technologies needed for the learning and diffusion of knowledge. The content, both textual and iconic, of various natures (detailed texts, image galleries, hypermedia presentations, hyperlink connections, video etc) is divided into three macro sections (technology, teaching and case studies), each of which is organised in thematic modules:

1. Learning Object of a Technological Nature: the training materials concern the transformations of new technologies and the possible effects on the training environment.

2. Learning Object with regard to Museum Teaching and Cultural Heritage: the contents refer to the main methodological aspects necessary for the design of museum teaching procedures and of the assets destined for different uses, with particular reference to the national and international guidelines.

\footnotetext{
${ }^{4}$ The display area is supported by Omeka, a platform that is easily installed and useful for sharing educational and cultural information online.

${ }^{5}$ The e-learning area is supported by Moodle (the acronym of Modular Object-Orientated Dynamic Learning Environment); it is a technological space for managing courses, based on a constructionist ideology that all learning is facilitated by the production of tangible objects. Moodle was created in 2002 by Martin Dougiamas, an administrator for the Curtin University Network in Australia. He has a degree in information technology (IT) and a one-year Master's degree in education. The idea for Moodle came from his studies for his doctoral thesis, never completed, on the use of free software to help social constructionist epistemology on teaching and learning within the community, with thoughtful questions, on the Internet[AU: Do edits to the sentence "The idea for Moodle..." convey the intended meaning?].
} 


\section{University museums and the Third Mission: the project "Young people for culture" in the Museum Laboratory of Education of Bologna University \\ Panciroli, Macauda}

3. Learning Object of In-Depth Case Studies: This refers to the teaching and educational experiences of good practice, achieved in scholastic and extra-scholastic contexts as a result of partnerships created between museums, archives and cultural institutes. This training area also offers places for documents to be displayed, notice boards supplied for the exchange of messages and spaces for the sharing of good practices.

The documentation area ${ }^{6}$ is composed of a technological area dedicated to the development of high-quality educational experiences for the teachers and educators. In this area, there is a vast useful database containing a body of documents of about 200 experiences achieved with the partnership between school, museum and territory.

Teachers and/or educators document their experiences at school or on the territory, aimed at young people, according to the standard of quality. For this reason, a method of documentation has been implemented. The use of this system has required accurate analyses and research comparing the international quality standards and an analytical study of the transferability of the items in the system. The division of the system has two fundamental levels for the analysis of educational experiences:

1. The identification plan, which communicates the data regarding the institution that is responsible for the experience, the referees, the partnerships, the year it was created, the targets of the initiative (infancy, adolescents, adults or families) and the number of participants, in addition to the relationship with training curricula, the creation of spaces and finally, the objectives;

2. The pedagogical plan, in which the educational intention of the project is explicitly addressed (whether focussed on primary literacy, research or active learning; on the reworking and construction of individuals and groups); the methodology utilised, the specific objects and targets reached, the synthetic description of the project and the materials produced.

\subsection{Activities in MOdE}

The MOdE allows its users/visitors and members of the community to practice the following activities:

- in the exhibition area, one can take an interactive tour in the thematic rooms and the studios in which the visitors can appreciate the works and objects displayed;

- in the e-learning area, you have access to teaching and training paths composed of modules (Learning Objects) and participate in online, cooperative activities (E-tivities) for the training and updating of educators and teachers, on the theme of cultural heritage and new technologies;

- in the documentation area, you can refer to the experiences of educational quality achieved in museums and cultural places (visit the routes for going from museum to school and school to museum), in national and international contexts, with the aim of improving the good practices with the assets; refer the open access database containing the relevant data sheets regarding the best educational experiences, made accessible to and able to be shared within the practical community and which are able to be replicated.

As described, MOdE promises to be a suitable framework for the training and continuous updating of museum educators/teachers and for the provision of training courses that combine e-learning with face-toface learning (blended learning).

\subsection{Proposed Project}

\footnotetext{
${ }^{6}$ The documentation area is supported by Drupal. It was created by a Belgian programmer called Dries Buytaer in 2000. Drupal is an open source software platform consisting of a content management system. It is a programme that allows the administrator to organise large quantities and varieties of content (images, documents, archives, etc.). The name Drupal is the English transliteration of the Belgian word druppel, which means drop. In reality, Drupal is derived from a typing error during the search for an available website dominion. Buytaert wanted to call the site "dorp" (in Dutch meaning "village", referring to the community orientation of the project).
} 


\section{University museums and the Third Mission: the project "Young people for culture" in the Museum Laboratory of Education of Bologna University \\ Panciroli, Macauda}

The project "Young people for heritage" is aimed at creating spaces for knowledge and for the sharing of training for specific professional skills in education and cultural heritage, paying particular attention to virtual platforms and to the new learning styles that are experimented there.

It is an appropriate training course that is specifically understood in terms of the development and strengthening of skills for educators and teachers, basically the main reference figures for the training of young people. In MOdE, these figures experiment new teaching methods of the heritage through the use of new technologies for learning. In fact, the main idea of the project is to produce and spread methodologies and innovative instruments for effective teaching of cultural heritage and the diffusion of related digital skills for educators and teachers, using the maximum potential of the e-learning environment (Hein, 1998, Bonaiuti, 2006, Panciroli, 2007, Romano, 2015). The assumption is that through technological systems for

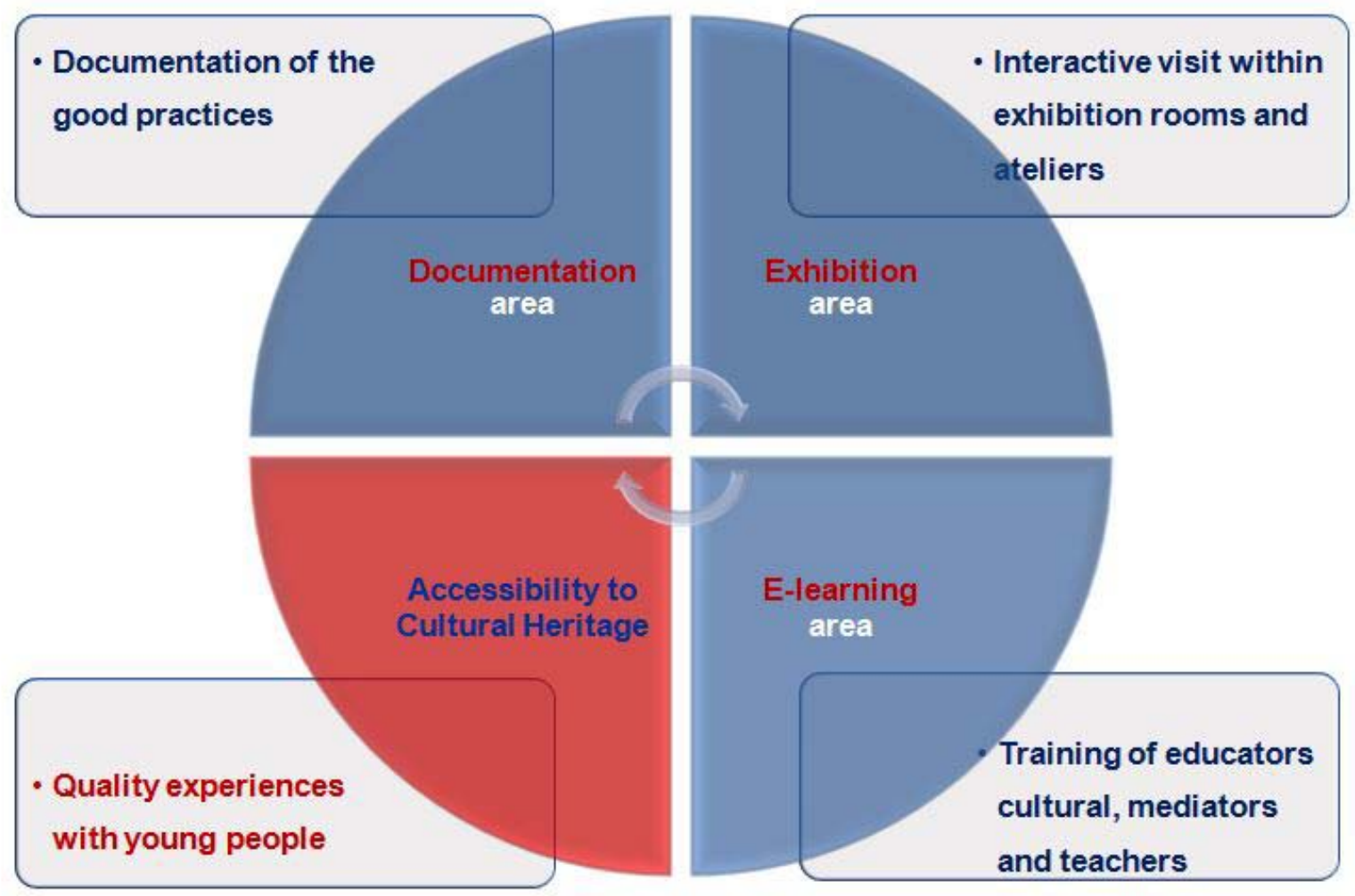

Fig. 2. The actions of the Project "Young people for culture" in MOdE

effective training, teachers and highly qualified educators can improve the professional performance, enhancing expertise on cultural heritage. Such methodologies and instruments will be created, implemented and experimented through the three areas of e-learning, exhibition and documentation of MOdE.

Therefore, through an integrated, joint training system in MOdE, teachers and educators are able to proceed autonomously towards the design and construction of teaching material, as well as towards the creation of cultural activities with heritage, following self-training strategies, shared training and the training "domino effect"; the students themselves thus in turn become teachers and help other students to do the same in a tiered structure for spreading knowledge. Furthermore, these professional figures that are united in a practical community (Wenger, 1998) are provided with a space in which they can confront each other, share good practices and find new sources of reflection and activities aimed at developing a quality system for the knowledge of the heritage, which ensures easy accessibility. 


\section{University museums and the Third Mission: the project "Young people for culture" in the Museum Laboratory of Education of Bologna University \\ Panciroli, Macauda}

In fact, we need to recognise the different meanings of the objects conserved in the museums or in other cultural places: "they have built dense layering around themselves, whether it is a historical object or they prepare to build it if the work or the findings have been extracted from the contemporary world, to ensure long-term conservation. It is on this complex layering system that in some ways we risk the museum's message and function of bringing knowledge and information to the public" (Lugli, 1992, p. 89).

Furthermore, the integrated areas for knowledge relating to cultural heritage, spread through this project, are an excuse to construct diverse groups of learners and to experiment with collaborative and innovative practices. These practices, through documentation and the sharing of high-quality educational experiences, are replicable and transferable so that we can improve the levels of learning and create an open and innovative pedagogy in education, training and the youth sector.

In particular, the teachings provided in the training sector, in terms of the knowledge valourisation of our cultural heritage, with a specific reference to the relationships that these assets establish with the social territory of belonging, are aimed at promoting new forms of active and responsible citizenship roles in all of the learners involved in the project, despite their different cultural backgrounds. In fact, the youth are the main targets for the educational experiences with culture. This permits them to have contact with social and cultural organisations in their regions, actively participating in the diffusion of events and displays, with the objective of promoting education in culture and social entrepreneurship among the youth. This is in line with the objective of the Third Mission. In fact, social welfare, the aim of the Third Mission, appears in this project as youth welfare, in which the youth acquaint themselves with the cultural heritage of the museums in the city to find their own cultural identity. The museum "from a container of cultural assets becomes the subject of culture,... for the transmission of its value to the community, to reinforce identity and social growth with particular emphasis on future generations" (Paraventi, 2007, p. 42).

The youth, guided by museum educators, cultural mediators and teachers, can acquire appropriate knowledge directly from the museums and cultural places, with the conviction that "we need to protect the direct contact with these works,... it is irreplaceable, if we want the museum to move forward according to a project regarding the true advancement in culture, not erudite or notional, and that it be a powerful motor of Humanitas" (Lugli, 1992, p. 91). The youth, in fact, are asked to do their own reading of the heritage through the design, creation and implementation of their own output.

To summarise, the project "Youth for Culture" is aimed at preparing and strengthening the professional profiles of valourisation of the cultural heritage, in particular, by the museum educators, cultural mediators and teachers, who according to a training system "domino effect" enable the students - in their own time - to become teachers and create quality experiences with the young people and the museum heritage. These experiences, documented subsequently using the quality form, implement the body of documentation to be shared in a practical community that is constantly growing, that is, a learning community in which professional growth is based on the sharing of experiences between experts in the fields of museum teaching and cultural heritage. These experts focus on and share a new model for the teaching of cultural heritage, passing from local to international works, through the creation of virtual partnerships between universities, museums, cultural institutions, schools and regional associations.

\section{References}

ANVUR (2013). Rapporto sullo stato del sistema universitario e della ricerca. Retrieved from http://www.anvur.org/attachments/article/644/Rapporto\%20ANVUR\%202013_UNIVERSITA\%20e\%20RICERCA integrale.pdf

ANVURR (2015). La valutazione della terza missione nelle università italiane - Manuale per la valutazione,. Retrieved from http://www.anvur.org/attachments/article/26/M .pdf

Bollo A. (Ed.) (2008). I pubblici dei musei. Conoscenza e Politiche, Milano: Franco Angeli.

Bonaiuti G. (2006). E-learning 2.0. Il futuro dell'apprendimento in rete, tra formale e informale. Trento: Centro Studi Erickson. 


\section{University museums and the Third Mission: the project "Young people for culture" in the Museum Laboratory of Education of Bologna University \\ Panciroli, Macauda}

Brunelli M. (2011). Heritage interpretation. Un nuovo approccio per l'educazione al patrimonio culturale, Macerata: EUM.

Buckingham D. (2007). Beyond technology: children's learning in the age of digital culture. Cambridge: Polity Press.

Calvani A., (Ed.) (2016). Fondamenti di didattica: teoria e prassi dei dispositivi formativi, Roma: Carocci.

Cataldo L., Paraventi M. (2007). Il museo oggi: linee guida per una museologia contemporanea. Milano: Hoepli.

Cenedella, C., Mascheroni S. (2014). Fonti del sapere. Didattica ed educazione al patrimonio culturale. Aicurzio (MB): Virtuosa-Mente.

De Biase, F. (Ed.) (2014). I pubblici della cultura: audience development, audience engagement, Milano: Franco Angeli.

E3M Project. (2012). Green Paper Fostering and Measuring 'Third Mission' in Higher Education Institutions. Brussels. Retrieved from http://www.e3mproject.eu/docs/Green\%20paper-p.pdf

Hein, G.E. (1998). Learning in the museum. London-New York: Routledge.

Hooper Greenhill, E. (1999). The educational role of the museum. London-New York: Routledge.

Lugli A. (1992). Museologia. Milano: Jaca book.

Mannino F. (2016). Musei e collezioni universitarie come welfare cognitivo. Retrieved from http://www.ilgiornaledellefondazioni.com/content/musei-e-collezioni-universitarie-come-welfare-cognitivo

Messina, L. (2015). Tecnologie, formazione e didattica. Roma: Carocci.

Padfield, C. et al. (2012). Green Paper. Fostering and Measuring 'Third Mission' in Higher Education Institutions. Retrieved from http://www.e3mproject.eu/docs/Green\%20paper-p.pdf

Panciroli, C. (2007). E-learning e formazione degli insegnanti. Azzano S.Paolo: Edizioni Junior.

Panciroli, C. (2013). La formazione nello sviluppo professionale delle insegnanti. In L. Balduzzi, M. Manini (Eds.), Professionalità e servizi per l'infanzia. Roma: Carocci.

Panciroli, C. (2015). Le valenze educative del bene culturale tra scuola e musei. In Formare al Patrimonio nella scuola e nei musei. Verona: QuiEdit.

Panciroli, C. (2016a), Los bienes culturales como patrimonio educativo, EARI. Educación Artística Revista de Investigación. Instituto de Creatividad e Innovaciones Educativas de la Universitat de València.

Panciroli, C. (2016b). El MOdE como un espacio de investigación expresiva: el ejemplo de los atelier. In Entornos informales para educar en artes. PUV Publicacions de la Universitat de València.

Panciroli, C. (2016c). Le professionalità educative tra scuola e musei: esperienze e metodi nell'arte. Milano: Guerini.

Romano, A. (2015). Dalla lectura all'e-learning. Bologna: CLUEB.

Sanderhoff, M. (2014). Sharing is caring: openness and sharing in the cultural heritage sector. Copenhagen: Statens Museum for Kunst.

Sobrero, M. Spigarelli F. (Ed.) (2015). La valutazione e gli indicatori di terza missione. Retrieved from http://www2.crui.it/crui/osservatorio/4_GdL\%204_Rapporto_def.pdf

UMAC. (2004). University Museums and Collections. Importance, Responsability, Maintenance, Disposal and Closure. Retrieved from http://publicus.culture.hu-berlin.de/umac/guidelines

Wenger, E. (1998). Communities of Practice. Learning, meaning and identity. London: Cambridge University Press. 